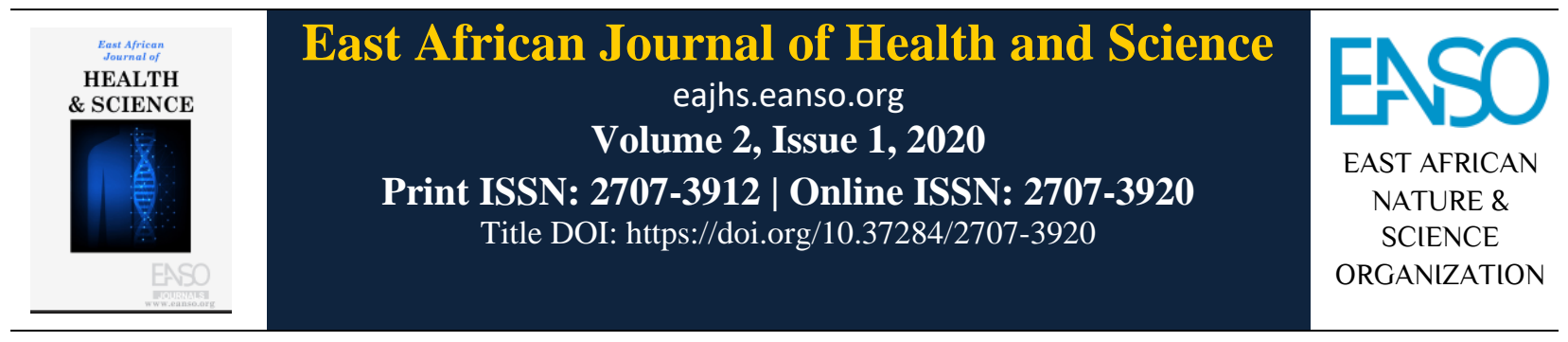

Original Article

\title{
Challenges of Adopting Local Visual Contents in Awareness Campaigns for Control of Communicable Diseases
}

\author{
Ebenezer Odji ${ }^{1 *}$, Wilson Truman Okaka², Johnson Yekini Obe ${ }^{3}$, \\ Blessing Chidubem Ario ${ }^{1}$ \& Deborah Oluwapelumi Adelakun ${ }^{4}$ \\ ${ }^{1}$ Federal University of Technology, Akure, P. M. B. 704 (c/o FUTA, Industrial Design), Nigeria. \\ ${ }^{2}$ Kyambogo University, Kampala, P. O. Box 1, Kyambogo, Uganda (c/o Teacher Education and Development Studies). \\ ${ }^{3}$ Federal Institute of Industrial Research, Oshodi, P. M. B. 21023 (c/o FIIRO, Ikeja, Lagos), Nigeria. \\ ${ }^{4}$ University College Leuven-Limburg, 3001 Geldenaaksebaan, Leuven (c/o UCLL, International Management), Belgium. \\ *Author for correspondence email: ezerodjimin@gmail.com.
}

Article DOI: https://doi.org/10.37284/eajhs.2.1.41

\section{Date Published: ABSTRACT}

23 November 2020 This paper asserts that public awareness creation and raising (ACR) adopting local-visual-evidences (LVE) have already been established by studies as an

Keywords: effective health communication strategy that can be employed to alleviate the outbreaks of communicable diseases. The purpose of the paper is to establish the

Awareness

Creation,

Communicable

Diseases,

Local-Visual-

Evidences,

LVE,

Non-Local-Visual-

Evidences,

NLVE,

Public Health. major challenges of effective implementation of this important risk communication strategy. This study was informed by relevant good practice, lessons learned, and the results of previous studies on awareness creation (AC) with a focus on communicable diseases in Nigeria. This review examined the probable prospects and challenges of adopting LVE-based AC contents to provide policymakers, public health, and safety agencies accessible information for effective decision-making options. The preliminary findings revealed that the use of LVE-based AC information services or contents is not favourable for the patients, their families, or friends when appropriate precautions are not taken. The same also applies to the government, public awareness communication campaigners or content designers, and their development partners or sponsors. However, the paper found that LVE-based public awareness communication campaigns would be effective in curbing the outbreaks of communicable diseases if effectively conducted at the community level. It is highly recommended that public awareness communication practitioners, governmental and nongovernmental organisations, involved in communicable disease management and prevention, know that participatory community engagement leads to higher awareness for behaviour change. The study proposed a LVE Adoption Pattern to guide decision-makers in crisis situations.

\section{APA CITATION}


Odji, E., Okaka, W., Obe, J., Ario, B., \& Adelakun, D. (2020). Challenges of Adopting Local Visual Contents in Awareness Campaigns for Control of Communicable Diseases. East African Journal of Health and Science, 2(1), 75-83. https://doi.org/10.37284/eajhs.2.1.41.

\section{CHICAGO CITATION}

Odji, Ebenezer, Wilson Okaka, Johnson Obe, Blessing Ario, and Deborah Adelakun. 2020. "Challenges of Adopting Local Visual Contents in Awareness Campaigns for Control of Communicable Diseases". East African Journal of Health and Science 2 (1), 75-83. https://doi.org/10.37284/eajhs.2.1.41.

\section{HARVARD CITATION}

Odji, E., Okaka, W., Obe, J., Ario, B. and Adelakun, D. (2020) "Challenges of Adopting Local Visual Contents in Awareness Campaigns for Control of Communicable Diseases", East African Journal of Health and Science, 2(1), pp. 75-83. doi: 10.37284/eajhs.2.1.41.

\section{IEEE CITATION}

E. Odji, W. Okaka, J. Obe, B. Ario and D. Adelakun, "Challenges of Adopting Local Visual Contents in Awareness Campaigns for Control of Communicable Diseases", EAJHS, vol. 2, no. 1, pp. 75-83, Nov. 2020.

\section{MLA CITATION}

Odji, Ebenezer, Wilson Okaka, Johnson Obe, Blessing Ario, and Deborah Adelakun. "Challenges of Adopting Local Visual Contents in Awareness Campaigns for Control of Communicable Diseases". East African Journal of Health and Science, Vol. 2, no. 1, Nov. 2020, pp. 75-83, doi:10.37284/eajhs.2.1.41.

\section{INTRODUCTION}

Ensuring public health service delivery is an inherently moral, policy, and ethical obligation for all health professionals, practitioners, and awareness creation (AC) content designers. This is primary since infectious and non-communicable diseases are among the most significant threats to human development in developing countries (Thomas, Sage, Dillenberg, \& Guillory, 2002). Various communicable diseases (CD) have over the years ravaged public health in the developing world (Neuberger, et al., 2012; WHO, 2014; Crompton, Malcolm, Cadet, Kelly, \& Degennaro, 2016; Nabil, 2018; Clive, Lacreisha, \& Nadine, 2019). From social and economic perspectives, CDs have for decades hampered sustainable development goals (SDGs) especially SDG 3 progress on universal access to quality primary healthcare in Africa (UN, 2015). Recent CDs outbreaks such as Lassa fever, Ebola, and the COVID-19 pandemic proved grievously challenging to contain or manage even for seemingly well-developed nations with the death toll for COVID-19 yet growing as at the time of this review (Odji, 2020; Odji, 2020b; WHO, 2020). Developing economies like the Western African nations have struggled to contain CDs such as COVID-19. It is feared that if CDs like the COVID-19 pandemic persists; many nations like Nigeria might become failed or fragile states as the citizens of some countries did not believe that it was a major threat to them due to a dearth of local visual evidences (LVE) substantiating their prevalence (Odji, 2020; Odji, 2020b; Odji, 2020c). Therefore, this study reviewed the need for the adoption of LVE based public awareness creation/education with a view to helping policymakers, relevant concerned agencies and actors make more informed decisions as a prevailing $\mathrm{CD}$ or other forms of crises may demand, with reference to some possible challenges that may accompany the recommended strategy.

\section{METHODS}

This paper was informed by a systematic literature review, policy analysis, relevant good practice, lessons learned, and results of previous studies on awareness creation with a focus on communicable diseases in Nigeria. This review examined the probable prospects and challenges of adopting local-visual-evidence-based AC contents to provide policymakers, public health, and safety agencies accessible information services for 
effective decision-making options. Additional information was obtained through multiple internet searches using popular search engines with a focus on the keywords. More data were obtained from national, regional, or international agencies including news bulletins, key informants, and informal email discussions on the issue.

\section{RESULTS AND DISCUSSION}

\section{Negative Attitudes towards Positive Health Messages}

Despite widespread AC in Africa, there were yet evidences of poor attitudinal responses to $\mathrm{CD}$ preventive health messages. Many locals in Nigeria for example, despite the high level of investment in awareness creation in the country, yet did not believe CDs such as COVID-19 existed or were as serious as the governments made it to look like. This negative belief system wrongly shaped their mind-sets or attitudes towards curbing of the CDs. The result was the spread of CD infections aggravated by negative behavioural tendencies like defying the standard CD prevention or control guidelines.

These negative attitudes towards positive persuasive health messages were attributed to reasons including ignorance (Odji, 2020c), false knowledge or misperception (Odji, 2020c), economic factor or financial survival pressures informed by poverty (Odji, 2020b; Qutieshat, 2020), poor persuasiveness of the adopted AC contents, statistics based policies i.e. lack of local visual evidences to substantiate $\mathrm{CD}$ prevalence claims (Odji, 2020b), selfishness (as individuals or groups who were not directly affected by the prevailing diseases had greater tendencies to be lax) and lack of trust in the message sponsors (i.e. governments). According to a recent study on the influence of attraction on attitudes and attitude confidence, the physical attraction of the source of a message can influence recipients' attitudes about the received message (Mello, Garcia-Marques,
Briñol, Cancela, \& Petty, 2020). Most of these challenges were knowledge/education-related.

Apparently, the shared characteristics of some of these challenges affirm the recommendations of previous studies for the adoption of $\mathrm{AC}$ as a $\mathrm{CD}$ preventive or control measure (Odji, 2020; Odji, 2020b; Okaka, 2018). However, for AC based preventive strategies to be effective, there is the need for active participants and agencies to seek the information required in specific localities so as to implement policies and programs that protect and promote health (Thomas et al, 2002) and other key sectors. According to the code of ethics, public health organisations and their employees should engage in collaborations and affiliations in ways that build the public's trust and the organisations' effectiveness (Thomas et al, 2002). For instance, the use of digital technology may be effective in controlling unethical social media contents like fake news (Maltby, Thornham, \& Bennett, 2015) which promotes false knowledge or ignorance.

\section{Public Access to Local Visual Evidences (LVE) and Advantages}

AC has been classified into two major categories: LVE based AC and NLVE (Non-Local Visual Evidence) based AC. NLVE based AC were campaigns adopting foreign visual evidences (Ibezim-Ohaeri, 2020). LVE-based AC were campaigns adopting local visual evidences for public awareness and or education. However, this classification depended on the place of application. For example, visual evidence harvested in Kenya or Uganda and adopted in Nigeria will be classified as NLVE. If the same evidence is adopted for AC in the country/region of harvest, it will be classified as an LVE.

While economic factors topped the list of reasons given for defying $\mathrm{CD}$ prevention or safety guidelines in Nigeria, the lack of Local Visual Evidence (LVE) to support the claims of the prevailing CDs turned out as the most common 
reasons for defying $\mathrm{CD}$ prevention or control guidelines (Odji, 2020b). According to the study, it is impossible to practice something correctly when we lack the necessary knowledge because ignorance is a key factor in spreading infectious diseases (Odji, 2020c). However, a study of COVID-19 spread in Nigeria, revealed that many Nigerians were not ignorant of the pandemic cause, yet they defied the COVID-19 standard operating procedures (SOPs) due to lack of LVE (Odji, 2020b). This reason was also confirmed by another study (Odji, 2020) identifying 'the lack of LVEs from the relevant government agencies as a cause. Therefore, local visual evidence-based policies were necessary for alleviating the rising toll of public health threats (McCambridge, Kypri, Sheldon, Madden, \& Babor, 2020).

This health education/promotion AC strategy, adoption of LVEs, was vital for obvious reasons which included:

1. Increased AC content believability

2. Optimised attention-arresting effectiveness

3. Consequently, improved message acceptability

4. Goal achievement e.g. reduced risks of CD prevalence.

AC contents are useless if attention is not given to them by the target audience (Odji, Oladumiye, \& Adelabu, 2016). The effectiveness of any persuasive content begins with the volume of attention it is able to arrest which, if the persuasive content is effective enough, is supposed to influence the audience to progress to targeted action(s) (Odji et al, 2016). The increased believability of the AC contents due to the adoption of more local-visual-contents was expected to yield greater attention arresting effectiveness. Audiences tended to take less seriously what they perceived only little or no believability from. Watching a close local community member or one's own country's citizen die helplessly in agony attracts greater attention and empathy than a foreign remote image presenting similar contexts.

If LVE could improve AC contents/message believability, improve acceptability and attention arresting effectiveness, then achieving the campaign goals is most feasible. Persuasion, deliberate attempts to motivate attitudinal or behavioural adjustments (Odji, 2020d), is more relatively achievable when the public has greater access to LVE as opposed to mere statistics so that $\mathrm{CD}$ prevalence claims will not be mistaken for mere political, economic or social propagandas as it was evidently prevalent in Nigeria as at the time of this review.

\section{Awareness Creation in CD Preventive, Management, or Control Strategies}

In the absence of a defined cure or vaccine for some CDs, there was a need to concentrate more on preventive and control measures (Zühlke \& Engel, 2013). Various preventive, management, or containment measures were put in place by disease control agencies in Nigeria and other African nations depending on the unique needs of their citizens, preparedness of their disease control agencies and the capacity of the nation to cope with an outbreak, epidemic or pandemic. Some of the measures were similar and so were summarised hereunder simple headings including but not limited to: health coordination meetings, health education/awareness creation, vector control, active periodic population or target group screening/tests, mass surveys to identification of affected areas, provision/enforcement of preventive/containment guidelines/measures, improved hygiene practices [including personal and environmental hygiene], early diagnosis and integrated management of illnesses or symptoms, support for $\mathrm{CD}$ victims and their families, provision of basic amenities, policy making/adjustment to cater for prevailing crisis situations and so on (Ampofo, n.d.; Zühlke et al, 
2013; WHO, 2014; Odji, 2020c; WHO, 2020). Prominent on the list was AC or health education.

The critical need for effective education and awareness creation strategies places the key focus on the health educators, peer influencers, media practitioners, and $\mathrm{AC}$ content designers as these must be addressed to prevent or control the spread of the CDs due to lack of awareness and knowledge (WHO, 2014; Abdulrahim, Alasasfeh, Khader, \& Iblan, 2019). According to the world health organisation (WHO), the supply of vaccines in Africa used to be over $99 \%$ from external sources and less than $1 \%$ internal production (Ampofo, n.d.) which leaves many African governments more with the AC options which was $100 \%$ under their controls.

However, for an awareness campaign to be effective in reaching a specific population, there was the need for it to contain contents with which members of the target population may readily relate (Odji, 2020) and the role of Indigenous Knowledge (IK) is highly prominent (Okaka, 2018). Hence, the adoption of more LVE based AC contents for optimised effective reach was recommended (Odji, 2020a; b). Unfortunately, this AC type is not without its disadvantages, some of which are highlighted below:

1. A bridge of the code of rights (of patients)

2. Bridge of professional trust

3. Stigmatisation of recognisable survivors

4. Risk of public panic and so on.

Although adopting LVE-based AC contents have been justifiably recommended in previous studies because of the obvious advantages it portended for greater effectiveness in combating the prevalence of $\mathrm{CD}$, it however possesses considerable ethical, legal and or moral challenges. For example, a patient has the right to privacy and confidentiality that must be assured at all stages of his/her treatment or monitoring. The patient has the right to be free from unwarranted public exposure, except in such cases as when the rights are waived by the patient him/herself, through a court order or when such is necessary for public health and safety (SAMCH, 2020). According to the guidelines of the University College Hospital, Ibadan (UCH), a patient expects that, within the confines of his/her rights as provided by the law, all communications concerning him/her shall be treated confidentially (UCH, 2019). Adoption of LVE may breach this code of medical practice. In addition, possible discrimination against $\mathrm{CD}$ or non-communicable disease (NCD) victims, recovered patients, next of kins, dependants, family, or friends (Hoffman, 1989; Meel, 2003; Mawar, Sahay, Pandit, \& Mahajan, 2005; Clarke \& Chess, 2008; Charles, 2007; Siu, 2008; Sheehan, Corrigan, Al-Khouja, \& The Stigma of Suicide Research Team, 2016; Stergiou-Kita, Pritlove, \& Kirsh, 2016) undermine the adoption or diffusion of LVE based AC contents in the society.

Obviously, the adoption of LVE based AC campaigns has its advantages, yet, its disadvantages, if not well provided for, may outweigh them. An effective attention arresting content may yield an increase in knowledge, but the increase in knowledge may not necessarily translate into targeted action or behavioural/attitudinal adjustments (Odji, 2020).

However, the need to urgently curb the prevalence of CDs such as COVID-19 demands rather drastic approaches which may include the adoption of LVE, despite the challenges attached, with the aim of saving lives where possible. Therefore, the adoption of LVE, when and if adopted, must be done with appropriate cautions effectively taken. For example, the figures of patients or other individuals involved in a harvested visual evidence intended to be adopted for AC content creation must be properly identity-screened, as recommended for example in a previous study (Odji, 2020b), to provide for possible plausible deniability both for the patients and the content 
designers or design sponsors. It is required that prudent public policies should be made and implemented only after proper problem identification and construction (Reiter-Palmon \& Robinson, 2009) has been carried out successfully. Public health information policies enacted in a hurry, especially during emergencies such as the COVID-19 pandemic outbreak must address the ethical rights of patients or victims and their families.

As shown in Figure 1, adoption of LVE is dependent on a liaison between realities and responsibility both on the path of the policymakers whose responsibility is to ensure the safety of public health and medical/health professionals whose responsibilities are their patients' interests and wellbeing.

\section{A Proposed LVE Adoption Pattern}

The following have been established already about the adoption of LVE:

1. LVE based AC has both advantages and disadvantages despite its established effectiveness in AC campaigns.

2. Is dependent upon ethical, professional codes of conduct and government policies.

3. Is dependent on the patient's consents and rights in relation to both professional conduct and government policies.

Figure 1: A Proposed LVE Adoption Pattern in Crisis Situations

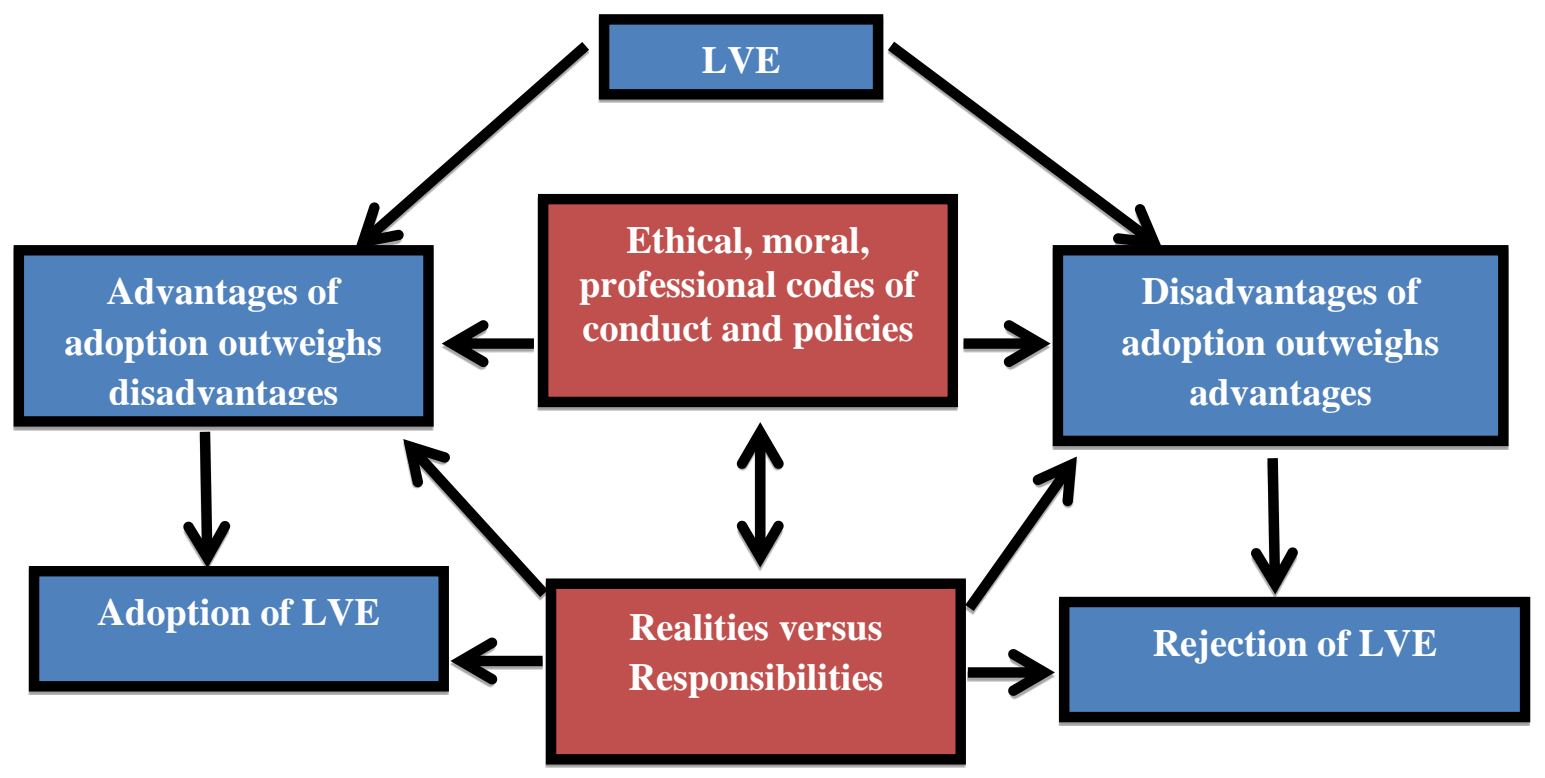

Therefore, as shown in Figure 1, for any crisis situation, if advantages outweigh disadvantages, LVE may be adopted. However, when disadvantages outweigh the advantages, LVE adoption may be rejected. Both cases, at every stage of consideration, are dependent on ethical or professional codes of conduct and prevailing policies. The decision for eventual adoption or rejection is dependent on a liaison between professional (medical/health practices), individual (patients' rights/privileges) and government or related agencies' responsibilities or rights and the realities presented by a prevailing crisis situation. 


\section{RECOMMENDATIONS}

The following recommendations are made for the early adoption of LVE for health AC effectiveness:

- Obtain a patient's informed written consent because the rights of a patient must not be violated by anyone, any agency, professional, or the government, therefore there is the need to officially obtain the written consent directly from a patient according to the right protocol. Ethical practices to protect a patient's privacy rights must be strictly observed.

- Establish a standard reward system to compensate patients who volunteer to allow their visual or personal data to be adopted in AC contents creations. Such proposed compensations may be extended directly to $\mathrm{CD}$ survivors or the appropriate, rightful, or legal persons or next of kin.

- The public should be educated against promoting stigma against $\mathrm{CD}$ survivors, especially those involved in campaign strategies for containing communicable diseases or risks to public health and safety practice.

- Adoption of LVE based AC contents should be done only with appropriate precautions taken as recommended.

- Public awareness communication practitioners, governmental and nongovernmental organisations that are involved in the management or prevention of the epidemic, should know that participatory community engagement leads to higher awareness for behaviour change to prevent or control the spread of communicable infections and health risks to public safety.

\section{CONCLUSION}

LVE based AC contents have already been established as the preferable alternative to adopt at the community/local level for the purpose of public awareness/education in containing or preventing $\mathrm{CD}$ or other public safety threats. However, adopting LVE based AC contents are not without downsides. It is really difficult deciding which AC content type to adopt and the 'code of rights' or 'code of ethics', for example, should serve as guides with reference to teaching, research, and/or use of data obtained from patients (both visual and non-visual).

So far, not all public policies agree with the principles stated by professional medical associations because many professional healthcare providers may find the adoption of LVEs uncomfortable for their professional responsibilities. The public policy-makers owe it to the public to protect their health and safety as a right. The decision for or against the adoption of LVE for health AC may then be hinged on the liaison between responsibility and reality.

\section{REFERENCES}

Abdulrahim, N., Alasasfeh, I., Khader, S. Y., \& Iblan, I. (2019). Knowledge, Awareness, and Compliance of Disease Surveillance and Notification Among Jordanian Physicians in Residency Programs. The Journal of Health CareOrganization, Provision, and Financing, 56, 1-6. DOI: 10.1177/0046958019856508.

Ampofo, W. (n.d.). Vaccine Manufacturing in Africa. Retrieved July 16, 2020, from who.int: https://www.who.int/immunization/research/for ums_and_initiatives/1_Wlliam_Ampofo_Vacci ne_Manufacturing_Africa.pdf?ua $=1$

Charles, A. E. (2007, October). Experiences of Stigma in Older Adults Living with HIV/AIDS: A Mixed-Methods Analysis. AIDS Patient Care and STDs, 21(10), 740-752. http://doi.org/10.1089/apc.2007.0010. 
Clarke, L., \& Chess, C. (2008, December). Elites and Panic: More to Fear than Fear Itself. Social Force, $\quad$ 87(2), 993-1014. https://doi.org/10.1353/sof.0.0155.

Clive, M. B., Lacreisha, E.-K., \& Nadine, J. G. (2019, June 24). Haiti; Destination Overview. Retrieved July 27, 2020, from cdc.gov: https://wwwnc.cdc.gov/travel/yellowbook/2020 /popular-itineraries/haiti

Crompton, L., Malcolm, S., Cadet, J., Kelly, M., \& Degennaro, V. (2016). Prevalence of noncommunicable diseases in rural Haiti. Annals of Global Health, 82(3), 539. DOI: 10.1016/j.aogh.2016.04.455.

Hoffman, B. (1989). Cancer survivors at work: job problems and illegal discrimination. Oncol Nurs Forum, 16(1), 39-43. https://pubmed.ncbi.nlm.nih.gov/2911527/.

Ibezim-Ohaeri, V. (2020, April 1). COVID-19, human rights and civic space in Nigeria. Retrieved June 14, 2020, from businessday.ng: https://businessday.ng/opinion/article/covid-19human-rights-and-civic-space-in-nigeria/

Maltby, S., Thornham, H., \& Bennett, D. (2015). Capability in the digital: institutional media management and its dis/contents. Information, Communication \& Society, 18(11), 1275-1296. DOI: 10.1080/1369118X.2015.1046893.

Mawar, N., Sahay, S., Pandit, A., \& Mahajan, U. (2005, December). The third phase of HIV pandemic: Social consequences of HIV/AIDSstigma \& discrimination \& future needs. Indian J Med Res., 122, 471-484.

McCambridge, J., Kypri, K., Sheldon, A. T., Madden, M., \& Babor, F. T. (2020, June). Advancing public health policymaking through research on the political strategies of alcohol industry actors. Journal of Public Health, 42(2), 262-269. https://doi.org/10.1093/pubmed/fdz031.

Meel, B. L. (2003). Suicide and HIV/AIDS in Transkei, South Africa. Anil Aggrawal's Internet Journal of Forensic Medicine and Toxicology,

4(1), https://www.anilaggrawal.com/ij/vol_004_no_ 001/papers/paper001.html.

Mello, J., Garcia-Marques, T., Briñol, P., Cancela, A., \& Petty, R. (2020). The influence of physical attractiveness on attitude confidence and resistance to change. Journal of Experimental Social Psychology, 90(2020), 112. https://doi.org/10.1016/j.jesp.2020.104018.

Nabil, A. N. (2018, May 24). A Review on Emerging and Reemerging of Infectious Diseases in Jordan: The Aftermath of the Syrian Crises. Canadian Journal of Infectious Diseases and Medical Microbiology, 2018, 1-8. https://doi.org/10.1155/2018/8679174.

Neuberger, A., Tenenboim, S., Golos, M., Pex, R., Krakowsky, Y., Urman, M., . . . Schwartz, E. (2012). Infectious Diseases Seen in a Primary Care Clinic in Leogane, Haiti. The American journal of tropical medicine and hygiene, 86(1), 11-5. DOI: 10.4269/ajtmh.2012.110426.

Odji, E. (2020, June). Limiting the Community Transmission of Communicable Disease Outbreaks through Local-Evidence-Based Awareness Creation. International Journal of Advanced Academic Research (Sciences, Technology and Engineering), 6(6), 12-31 DOI: 10.46654/ij.24889849.e6618.

Odji, E. (2020b). Curbing COVID-19 Prevalence and Other Communicable Diseases: The Laxity of Non-Local-Evidence-Based Awareness Creation. International Journal of Advanced Academic Research | Sciences, Technology and Engineering, 6(5), 66-80. DOI: 10.46654/ij.24889849.e6528.

Odji, E. (2020c). Roles of Children in the Proliferation of Communicable Diseases in Nigerian Rural Communities: A Designer's Perspective. International Journal of Health and Pharmaceutical Research, 5(3), 7-28. DOI: 10.5281/zenodo.3881081.

Odji, E. (2020d, October). Influencing Children: Limitations of the Computer-HumanInteractive Persuasive Systems in Developing Societies. International Journal of Modern 
Education and Computer Science, 12(5), 1-15 DOI: 10.5815/ijmecs.2020.05.01.

Odji, E., Oladumiye, E. B., \& Adelabu, O. S. (2016). The Recall and Communicative Effectiveness of Computer Generated Imagery in Television Advertisements; A Case Study of Lagos, Nigeria. KEER 2016 International Conference on Kansei Engineering and Emotion Research. University of Leeds. University of Leeds, 31 August - 2 September. http://doi.org/10.5281/zenodo.3952546: Japan Society of Kensei Engineering (JSKE).

Okaka, W. T. (2018). Effectiveness of Indigenous $\mathrm{K}$ n o w l e d g e i n Herbal Medicine in Combating Climate Health Effects in East Africa: The Role of Climate Information Services (CIS) for Local Adaptation. 13 International conference on understanding weather and climate extremes: our common future at: Starbucks Hotel, Eldoret, Kenya. Kyambogo University, Kampala, Uganda.

Qutieshat, R. J. (2020). Geo-database for Poor Families to Enhance Poverty Counter Efforts, Evidence from Jordan. Jordan Journal of Social Sciences, 13(1), 125-134. https://journals.ju.edu.jo/JJSS/article/view/107 088 .

Reiter-Palmon, R., \& Robinson, E. J. (2009). Problem Identification and Construction: What Do We Know, What Is the Future? Psychology of Aesthetics Creativity and the Arts, 3(1), 4347. DOI: 10.1037/a0014629.

SAMCH. (2020, March 18). Patient Rights: The Rights of the Patients. (Department of Health, Republic of Philippines, Producer, \& St. Anthony Mother and Child Hospital (SAMCH), Cebu City) Retrieved July 17, 2020, from samch.doh.gov: http://samch.doh.gov.ph/index.php/patientsand-visitors-corner/patients-rights

Sheehan, L. L., Corrigan, W. P., Al-Khouja, A. M., \& The Stigma of Suicide Research Team. (2016, August). Stakeholder Perspectives on the Stigma of Suicide Attempt Survivors. Crisis, 38, 73-81. https://doi.org/10.1027/02275910/a000413.
Siu, Y.-m. J. (2008, June). The SARS-Associated Stigma of SARS Victims in the Post-SARS Era of Hong Kong. Qualitative Health Research, 18(6), 729-738. https://doi.org/10.1177/1049732308318372.

Stergiou-Kita, M., Pritlove, C., \& Kirsh, B. (2016). The "Big C"-stigma, cancer, and workplace discrimination. J. Cancer Surviv., 10(6), 1035-1050. DOI: 10.1007/s11764-0160547-2.

Thomas, C. J., Sage, M., Dillenberg, J., \& Guillory, J. V. (2002, July). A Code of Ethics for Public Health. Am J Public Health, 92(7), 1057-1059. DOI: 10.2105/ajph.92.7.1057.

UCH. (2019). Patient's Rights and Responsibilities. (University College Hospital, Ibadan (UCH)) Retrieved July 17, 2020, from uch-ibadan.org.ng: https://uchibadan.org.ng/patients-rights-andresponsibilities/\#: :text=To\%20respect\%20the $\% 20$ competence $\% 20$ of, $\% 2$ Fhospital\%20is\%20 desirable $\% 2$ Fdesired.

UN. (2015). Sustainable Development Goals 2030,. New York: USA: United Nations (UN).

WHO. (2014). Communicable Disease Toolkit Liberia: 1 Communicable Disease Profile (WHO/CDS/2004.24). WHO Office, Liberia: World Health Organization (WHO) Regional Office for Africa (AFRO).

WHO. (2020). COVID-19 Situation Update for WHO African Region 24th June, 2020. World Health Organization, Regional Office for Africa.

Zühlke, L. J., \& Engel, E. M. (2013, September). The Importance of Awareness and Education in Prevention and Control of RHD. Global Heart, 8(3), 235-239. 